\title{
Comparative analysis of chemical composition of Miscanthus var. Soranovskii
}

\author{
Yulia A. Gismatulina*, and Vera V. Budaeva \\ Institute for Problems of Chemical and Energetic Technologies, Siberian Branch of the Russian \\ Academy of Sciences (IPCET SB RAS), 659322 Biysk, Russia
}

\begin{abstract}
The search for alternative sources of cellulose is currently getting special importance. Miscanthus holds promise as a cellulosic feedstock with a high potential for industrial-scale cultivation. The present study reports an analysis done for seven years of the chemical composition of the aboveground biomass of Miscanthus var. Soranovskii as a source for producing bioethanol. The aboveground biomass of Miscanthus was found to have a high cellulose content (about 50\%), irrespective of the age, and it is therefore reasonable to utilize this cultivar for bioethanol production.
\end{abstract}

Today, of special relevance are efforts focused on rendering plant cellulosic biomass into bioethanol with subsequent production of ethylene and other valuable carbohydrate polymers are now gaining ground (Skiba, 2017). The choice of a raw material for the obtention of bioethanol is usually guided by the cumulative indicator-ethanol yield from 1 ha-which takes into account crop yielding capacity and productivity in ethanol depending on sugar, cellulose or starch content. In Russia, Miscanthus has high potential for breeding at an industrial scale. Miscanthus is a perennial, fast-growing energy crop that provides high biomass yields of 10-15 t/ha/year over a span of 15-25 years, with low requirements for growing conditions (Gismatulina, 2017). Miscanthus offers a range of advantages: high cellulose content (50\%); unpretentiousness to soils and frost resistantance; low requirements for fertilizer application; and enhanced tolerance to diseases and pests. This complex of properties suggests a promising outlook for using Miscanthus to create a sustainable raw materials database for ethanol production.

Having regard to the above, this work was aimed at analyzing the chemical composition of the aboveground biomass of Miscanthus var. Soranovskii at each year over the span of seven years in order to assess the prospects of obtaining bioethanol therefrom.

The substrate for this study was seven Miscanthus var. Soranovskii (Slynko, 2013). To assess the prospects of producing bioethanol from Miscanthus, it was necessary to examine its chemical composition. For the examination, we took the aboveground biomass of Miscanthus var. Soranovskii over the span of seven years (2011-2017), which had been grown on experimental land plots of IPCET SB RAS (Biysk) completely without using agricultural methods (fertilization, watering, loosening and weeding).

The chemical compositions were measured by standard analytical procedures for plant biomass (Obolenskaya, 1991).

\footnotetext{
* Corresponding author: julja.gismatulina@rambler.ru
} 
The work was performed using instruments of the Biysk Regional Center for Shared Use of Scientific Equipment of the SB RAS (IPCET SB RAS, Biysk).

Table 1 summarizes chemical compositions of the aboveground biomass of Miscanthus var. Soranovskii harvested at each year over the period of seven years.

Table 1. Chemical compositions of the aboveground biomass of Miscanthus var. Soranovskii for the period of 2011-2017

\begin{tabular}{|l|c|c|c|c|c|}
\hline Harvest year & \multicolumn{5}{|c|}{ Content*, \% } \\
\cline { 2 - 6 } & $\begin{array}{l}\text { Kuschner } \\
\text { cellulose }\end{array}$ & Ash & Lignin & Pentosans & Fat-wax \\
\hline 2011 / 1 year-old & 42 & 6.30 & 22.23 & 25.33 & 5.71 \\
\hline 2012 / 2 year-old & 44 & 6.20 & 23.81 & 23.59 & 4.78 \\
\hline 2013 / 3-year-old & 45 & 4.62 & 21.11 & 25.10 & 2.81 \\
\hline 2014 / 4 year-old & 53 & 5.87 & 21.99 & 21.00 & 4.98 \\
\hline 2015 / 5 year-old & 54 & 3.57 & 20.13 & 18.57 & 3.57 \\
\hline 2016 / 6 year-old & 50 & 3.24 & 22.35 & 20.40 & 4.46 \\
\hline 2017 / 7 year-old & 50 & 5.06 & 23.08 & 20.44 & 4.86 \\
\hline Note: * on an oven-dry basis. & & & & \\
\hline
\end{tabular}

It follows from the tabulated data that Miscanthus var. Soranovskii holds promise as a cellulosic resource containing 42-54\% Kuschner cellulose, therefore, the obtention of bioethanol therefrom is expedient. The Kuschner cellulose content was observed to rapidly increase over the initial five years of harvesting, from $42 \%$ (harvest of the year 2011) to 54 $\%$ (harvest of the year 2015). The cellulose content then insignificantly declined from 54 $\%$ (2015 harvest) to $50 \%$ (2016-2017 harvests) and remained at this level for two years. No regularities of the variation of the non-cellulosics content were noticed over the years of this study.

Overall, it was found in the course of the study on the chemical composition of the aboveground biomass of Miscanthus var. Soranovskii throughout seven years that Miscanthus has a Kuschner cellulose content of about $50 \%$, and it is reasonable to utilize it for bioethanol production.

The research was supported by Integrated Program of Basic Research of the SB RAS II.1 'Interdisciplinary Integrated Research' (Project No. 0385-2018-0013).

\section{References}

1. E.A. Skiba, O.V. Baibakova, V.V. Budaeva, I.N. Pavlov, M.S. Vasilishin, E.I. Makarova, G.V. Sakovich, E.V. Ovchinnikova, S.P. Banzaraktsaeva, N.V. Vernikovskaya, V.A. Chumachenko, Chem. Eng. J. 329, 178 (2017)

2. Yu.A. Gismatulina, V.V. Budaeva, Ind. Crop. Prod. 109, 227 (2017)

3. N.M. Slynko, T.N. Goryachkovskaya, S.V. Shekhovtsov, S.V. Bannikova, N.V. Burmakina, K.V. Starostin, A.S. Rozanov, N.N. Nechiporenko, S.G. Veprev, V.K. Shumny, N.A. Kolchanov, S.E. Peltek, Vavilov Journal of Genetics and Breeding 17, 765 (2013)

4. A.V. Obolenskaya, Z.P. Yelnitskaya, A.A. Leonovich, Laboratory Works on Wood and Cellulose Chemistry (EDP Ecology, Moscow, 1991) 